\title{
CIENCIA, NATURALEZA Y PAISAJE EN ALEXANDER VON HUMBOLDT
}

\author{
Manuel Corbera Millán \\ Departamento de Geografía, Urbanismo y Ordenación del Territorio. Universidad de Cantabria' \\ manuel.corbera@unican.es
}

\section{RESUMEN}

Alexander von Humboldt es hoy reivindicado como el primero que entendió el paisaje geográfico en el sentido moderno y también como un referente importante del pensamiento ecologista. No deja de resultar paradójico el que las concepciones de un naturalista que trabajó entre los siglos XVIII y XIX, del último sabio del Renacimiento como algunos le califican por su saber universalista, puedan tener en la actualidad relevancia y coincidir con formulaciones actuales en el terreno de la Geografía y de la Ecología, y que además sus ideas no hayan tenido seguidores en esas disciplinas hasta tiempos recientes. Este trabajo trata de profundizar en esas concepciones humboldtianas y en su procedencia, una labor que se considera previa para valorar realmente su influencia actual.

Palabras clave: Humboldt, Naturaleza, Paisaje, Ciencia, Filosofía romántica

\section{ABSTRACT}

Alexander von Humboldt is today claimed as the first to understand the geographic landscape in the modern sense and also as an important benchmark of ecological thinking. That the conceptions of a naturalist who worked and lived between the eighteenth and nineteenth centuries, the last wise man of the Renaissance as some have qualified him for his universal

Fecha de recepción: febrero 2012.

Fecha de aceptación: febrero 2013.

1 Miembro del grupo de investigación de Geografía Histórica del Paisaje. Este trabajo ha sido desarrollado en el marco del proyecto I+D+i Las unidades básicas del paisaje agrario en España: Identificación, delimitación, caracterización y valoración. La España Atlántica y Navarra (referencia: CSO2009-12225-C05-04). Tengo que agradecer a José Sierra Álvarez las sugerencias que me hizo tanto en las conversaciones que mantuvimos durante el tiempo de elaboración de este artículo, como tras la lectura de un borrador previo a esta redacción. Me hago, en todo caso, único responsable de las ideas que aparecen en el texto. 
knowledge, had relevance today and that his ideas coincided with current formulations in the field of Geography and Ecology, seem was paradoxical. And same it's, on the other hand, that his ideas wouldn't have had followers in those disciplines until recent times. This paper attempts to explore the conception of Humboldt and in their origin, a task that is considered previous to truly assess their current influence.

Key words: Humboldt, Nature, Landscape, Science, Philosophy romantic.

\section{INTRODUCCIÓN}

Desde hace ya casi tres lustros, coincidiendo con lo que se ha llamado «la recuperación del paisaje», se viene reivindicando la figura de Alexander von Humboldt como el precursor de la actual concepción paisajística de la Geografía, que, en resumidas cuentas, propone una doble perspectiva del mismo, la sensible (subjetiva) y la analítica (objetiva) (Ortega Cantero, 2006; Martínez de Pisón, 2008; Gómez Mendoza, 2008; Besse, 2010). Y con frecuencia también se le atribuye una cierta ascendencia en el pensamiento ecologista, dadas sus ideas sobre el orden de la naturaleza y la integración del hombre en la misma.

No deja de resultar paradójico ese mirar hacia atrás a la búsqueda de las raíces de lo moderno, y no hacia el atrás inmediato, sino hacia otro más remoto. ¿Cómo la concepción de la naturaleza y del paisaje de un naturalista que trabajó y vivió durante el último tercio del siglo XVIII y la primera mitad del XIX puede haber conectado directamente con la que actualmente parece dominante? Para muchos Humboldt fue el último sabio universalista, más próximo a los pensadores del Renacimiento que de los científicos modernos. Por otra parte, no parece haber tenido seguidores inmediatos. Si exceptuamos algunos trabajos de Reclus y los primeros de Vidal de la Blache, en los que se pueden encontrar referencias paisajísticas, los primeros geógrafos que tras él recuperaron el paisaje como objeto de estudio (Passargue, Schluter...) trabajaron medio siglo después de su muerte, y de hecho reinventaron el término, le dieron un contenido semántico propiamente geográfico, desprovisto de sus aspectos subjetivos y sensibles; el paisaje pasó a ser objetivo, fisonomía real del espacio geográfico. Y en materia ambiental la distancia es mayor, y tampoco está nada claro que su concepto de naturaleza sea en realidad útil al discurso ecologista.

Este trabajo, sin embargo, no entrará a valorar ni las concepciones actuales dominantes de paisaje ni de naturaleza. Tampoco tratará de explicar las razones de la supuesta recuperación de las ideas humboldtiana. Previamente a ello parece necesario conocer con más detalle esas ideas, es decir, cómo entendía Humboldt la naturaleza y el paisaje y de dónde procedían tales concepciones. Por eso nos conformaremos aquí con ese objetivo. Trataremos de comprenderlas y explicarlas, intentaremos reconocer en qué medida se hacen explícitas y cómo se formulan en su obra ${ }^{2}$. Para ello, tendremos primero que reconocer el entorno cultural en el que el naturalista se movió; destacar y conocer las ideas de aquellos que pudieron tener

2 Se han elegido para este análisis aquellas obras más descriptivas y conceptuales de Humboldt: Cosmos , en la edición facsímil de la traducción de Francisco Díaz Quintero publicada por el Real Instituto y Observatorio de San Fernando en los años 1851-52 (tomos 1 y 2); Cuadros de la Naturaleza, según la traducción de Bernardo Giner de los Ríos; Ideas para una geografía de las plantas más un cuadro de los países tropicales, traducción de Ernesto Gubl realizada de la versión que Humboldt escribió en alemán en 1807; Vistas de las Cordilleras y monumentos de 
más influencia sobre él, para finalmente analizar en su obra esas concepciones y reconocer su filiación con relación al entorno científico, filosófico y artístico en el que le tocó vivir.

\section{ENTORNO CIENTÍFICO CULTURAL DE HUMBOLDT}

Humboldt vivió una larga vida (1769-1859), casi noventa años repartidos entre el último tercio del siglo XVIII y casi seis décadas del XIX. Como dijeron ya hace años Josefina Gómez Mendoza, Julio Muñoz y Nicolás Ortega, fue tributario de una triple perspectiva cultural, la del racionalismo ilustrado -que reunía la influencia del racionalismo francés y de la ilustración alemana-, la del romanticismo alemán y la del positivismo (Gómez Mendoza, Muñoz Jiménez y Ortega Cantero, 1994). Tradiciones a veces contradictorias y cuya convivencia en su pensamiento sólo puede entenderse como producto de un marcado eclecticismo. Humboldt era un ecléctico (Minguet, 2003, 80) a la manera en que Diderot entendía el término, es decir, como aquel que toma todo aquello que le interesa y después de cribarlo lo incorpora a la construcción de su discurso (Introducción de M. Jalón a Diderot, 1992, XXXIV).

Durante su infancia, adolescencia e incluso su primera juventud, su educación (como la de su hermano Wilhelm) fue tutorada por un preceptor profundamente rousseauniano, Gottlob Christian Kunth, que lo introdujo en la afición por la naturaleza acercando su educación a la misma, tanto a través del contacto directo como en la recomendación de lecturas, entre las que destacaban las de los viajes de exploración que venían llevándose a cabo en el siglo XVIII (Povedano Marrugat, 2008, 140). Viajes como el de Roggewin (1721-23) que descubrió la isla de Pascua, o como el del almirante Aston (1741), o la expedición de La Condamine por el Amazonas (1745), la de Carsten Niebuhr a Arabia (1761-63), la de James Bruce a las fuentes del Nilo Azul (1768-73), o los viajes de Bayron (1764-66), de Wallas y Carteret (1766-68) (Bougainville, 1966, 12-13), de Bougainville (1766-69), a quien Humboldt llegó a conocer cuando ya tenía más de 70 años y con el que concertó una expedición que no llegó a realizarse, y sobre todo los tres viajes del capitán Cook (1768-71, 1772-75 y 1776-79). Humboldt leyó y releyó sus a veces excelentes narraciones, sobre todo la de la segunda expedición del Cook escrita por su amigo el naturalista Georg Forster (A Voyage Round the World), con el que realizaría un viaje por el bajo Rhin y Londres en 1790. Todas estas lecturas, las pinturas de paisajes del pintor William Hodges (que también había acompañado a Cook en el segundo viaje), junto con la visión idealizada que ofrecían Rousseau, Buffon y Bernardin de Saint-Pierre, contribuyeron decisivamente a fomentar su afición viajera y su inclinación por los trópicos. Su gran viaje americano (1799-1804) acompañado de su amigo el botánico Aimé Bonpland, significó la realización de un sueño acariciado durante mucho tiempo y le proporcionó la parte más sustancial de su material de investigación.

Por otro lado, Humboldt había nacido en el tiempo en que comenzó a cambiar la concepción de la naturaleza y de su funcionamiento. Newton la había descrito como una gran máquina que se movía conforme a leyes precisas, que necesitaban ser descubiertas por medios científicos, experimentales y analíticos. Una concepción materialista pero también

los pueblos indígenas de América. en la versión publicada en 2010 por el CSIC, y la parte del gran viaje publicada por Planeta en 2005 y titulada Del Orinoco al Amazonas. Viaje a las regiones equinocciales del Nuevo Continente. 
mecanicista de la naturaleza, muy vinculada a los éxitos alcanzados por la física y las matemáticas. Fue precisamente en el tiempo de Humboldt enriqueciéndose conforme se desarrollaron otros ámbitos de las ciencias naturales, como la biología, que se inicia realmente con Buffon, o la química moderna, que lo hace con Levoisier. Avances en el conocimiento de la naturaleza cuyo fin era permitir al hombre un mayor poder sobre la misma, facilitar su explotación posibilitando así el progreso, tan ilimitado como el propio avance del saber y de la ciencia. Humboldt se formó en este espíritu positivista y de fascinación por la naturaleza. Tuvo buenos maestros y además buscó continuamente la amistad de los más destacados físicos y naturalistas de la época. Entre sus profesores cabe destacar Johanm Fiedrich Blumenbach, médico, zoólogo y uno de los padres de la antropología física y de la anatomía comparativa; Abraham Werner, geólogo defensor del neptunismo como hipótesis de formación de los continentes; Karl Willdenow, eminente botánico que probablemente le transmitió su interés por la distribución geográfica de las plantas y su relación con las condiciones climáticas. Entre sus amigos Georg Forster, naturalista (como tal formaba parte del equipo de Cook) que también llamó su atención sobre la correlación entre las especies vegetales y el clima; Leopoldo von Buch, a quien Humboldt consideraba como el geólogo más relevante de la época. Siguió de cerca los experimentos de Galvani y Volta sobre la electricidad (incluso experimentó en sí mismo y más tarde con las anguilas eléctricas del Orinoco), y a su regreso del gran viaje, instalado en París, cultivó la amistad y colaboró en distintos proyectos con Gay-Lussac y el físico François Arago.

Como contrapunto de su sólida formación científica, positivista y materialista, Humboldt conoció y se familiarizó con el paradigma idealista y romántico de la filosofía de la naturaleza alemana, que, en términos generales, entendía ésta como un Todo, una Unidad global. La idea holista de naturaleza no era extraña tampoco a los materialistas ilustrados, que la concebían en un sentido de encadenamiento de todos los seres (idea por otra parte platónica) y de todas las causas y efectos (Diderot, 1992, 15). Los idealistas alemanes la entendían, sin embargo, en su forma ideal, como un todo absoluto e inabordable por la vía científica, sólo accesible por la intuición sensible, a través del arte, de la belleza y de la estética, y profesaban, por ello, un auténtico panteismo. Humboldt tuvo ocasión de tratar directamente a algunos de sus máximos representantes. Había preparado su viaje americano en Jena, ciudad alemana que reunía a buena parte del pensamiento idealista romántico, el llamado «círculo romántico de Jena» del que formaban parte Novalis, Schelling y los hermanos Schlegel. Su relación, en todo caso, fue mucho más estrecha con Schiller y Goethe, a quienes había conocido también en esa ciudad por medio de su hermano Wilhein en 1794 y con quienes, sobre todo con Goethe, mantendría desde entonces una buena amistad. Los trabajos científicos de este último, particularmente la Teoría de la naturaleza y la Metamorfosis de las plantas (publicados en 1789 y 1790 respectivamente), conectaban mejor con su espíritu positivista e incluso con sus principales centros de interés, la geología y la botánica.

En qué medida las ideas de la filosofía de la naturaleza penetraron en Humboldt viene siendo ya un largo debate entre los estudiosos de su obra. Hay quienes afirman que su influencia sólo es perceptible en lo que hace a su sensibilidad romántica. Pero ¿qué significa eso? ¿se reduce a una cuestión de gusto? D’Angelo considera, por ejemplo, que el romanticismo no es únicamente un determinado sentido del gusto o de sensibilidad, sino que es realmente una filosofía que impregna totalmente la concepción de la naturaleza y del arte (D’Angelo, 
1999, 14-15). Lo cierto es que para entender sus ideas acerca de la naturaleza y el paisaje parece necesario indagar sobre el alcance de dicha influencia. Y para ello conviene conocer un poco más de cerca las ideas de la filosofía de la naturaleza. Se han seleccionado, para esta aproximación, a dos representantes de la misma: Friedrich von Schelling y Johann Wofgang Goethe; en el segundo caso por su conocida amistad y su reconocida influencia; en el primero por el fuerte peso que tuvo entre los filósofos idealistas, razón por la cual Humboldt le tenía en gran consideración ${ }^{3}$, a la vez que hacia él (y quizás hacia Hegel) parecen dirigidas algunas de sus críticas en Cosmos al idealismo más especulativo. Tanto en Goethe como en Schelling la idea del paisaje se encuentra íntimamente relacionada con la de naturaleza y con su forma de aproximación al conocimiento de la misma.

\section{NATURALEZA Y PAISAJE EN EL IDEALISMO ALEMÁN}

\section{Friedrich von Schelling}

Junto con Fichte es probablemente uno de los más destacados representantes del idealismo romántico alemán. Su sistema filosófico es sumamente especulativo y complejo. Según él, en la naturaleza habría que distinguir entre los meros productos y objetos (natura naturata) y el sujeto o fuerza productiva (natura naturans), una diferenciación que había tomado de Spinoza y que éste a su vez había recuperado de Aristóteles y Averroes. La naturaleza, por tanto, produce y reproduce los objetos materiales que la componen desde su fuerza creadora, identificada con el espíritu, que es el principio de la actividad y el movimiento, al igual que la materia lo es del reposo y la quietud (Schelling, 2004, 144). Pero, por una parte, el espíritu de la naturaleza se encuentra en estado inconsciente y, por otra, los objetos no son absolutamente pasivos, sino que conservan su fuerza productiva. De hecho, la materia inorgánica es considerada por Schelling también como materia viva dotada de organización, es decir, es un organismo. Pero se encuentra en el estadio más bajo, en lo que llama la primera potencia: no responde a estímulos y, por tanto, carece de toda conciencia. En los seres orgánicos comienza a aparecer la conciencia en sí, en la medida en que responden a estímulos mediante la irritación y el movimiento. Y así se continúa avanzando hasta alcanzar la máxima potencia, la conciencia de su propia existencia, que se produce sólo en el hombre, en el que aparece el espíritu consciente, el ojo con el que el espíritu de la naturaleza se contempla a sí mismo. El camino se recorre al revés desde el espíritu, que al buscar su origen lo encuentra en la naturaleza. De ese modo objeto y sujeto, naturaleza y espíritu, se identifican, son en realidad idénticos porque forman parte de lo que Schelling llama «lo absoluto» o también «lo incondicionado», que en realidad debe entenderse como la génesis o mejor como la historia del espíritu de la naturaleza, como el camino que reúne lo condicionado con lo incondicionado, el objeto con el sujeto, la naturaleza con el espíritu.

Schelling reconoce dos formas de aproximación a la naturaleza. La física empírica que se ocuparía de los objetos, es decir, del natura naturata, cuyo recorrido es lento y limitado, ya que nunca llegará a la última fuente del movimiento de la naturaleza porque no puede

3 En el prólogo de Ideas para una geografía de las plantas lo califica como «uno de los pensadores más profundos de nuestro siglo». 
alcanzar lo absoluto. Esta vía no deja por ello de ser útil, porque la naturaleza es un «Todo»y funciona como un sistema en el que existe una conexión entre todo lo que ocurre en ella. La física experimental puede y debe ocuparse de los innumerables «intermediarios» que aparecen conectados con las condiciones últimas de la naturaleza, pero cada nuevo descubrimiento nos devuelve a una nueva ignorancia y mientras se desata un nudo otro se ata. La segunda de las formas de aproximación es la de la filosofía, una física especulativa que dejando de lado los «intermediarios» sólo se ocupa de las causas originarias, del movimiento de la naturaleza, esto es, únicamente de las manifestaciones dinámicas, por lo que se la puede considerar también una física dinámica (Schelling, 1996, 123-127). Al conocimiento de lo absoluto se accedería directamente, por medio de la intuición intelectual a partir de los objetos de la naturaleza, que al formar parte del Todo, de la génesis, constituyen puertas para que lo absoluto se muestre.

Por otra parte, el arte constituye también una vía directa para el reconocimiento de lo absoluto, en este caso a partir de la intuición estética y desde la belleza, que es la idea que todo lo unifica ${ }^{4}$ y que junto con la verdad son dos modos de considerar lo absoluto. Pero para que la obra de arte refleje lo absoluto debe imitar a la naturaleza, aunque no miméticamente a sus objetos sino su capacidad creadora. De hecho Schelling es un precursor de la ruptura con la tradición imitadora en el arte. Según su concepción imitar a la naturaleza significa realmente crear; la obra de arte debe constituir un vínculo activo entre el alma y la naturaleza y sólo pueden ser entendidas y captadas en el contexto de ese vivo medio entre ambas» (Schelling, 2004, 116-117). Sólo desde ese vínculo será posible reconocer lo absoluto.

Schelling, sin embargo, no se refiere específicamente al paisaje. Es más, prefiere los temas mitológicos o religiosos, porque las artes plásticas sólo pueden alcanzar su verdadera cima en ... todo aquello que ya son según la idea o el alma, esto es, en las naturalezas divinas (Schelling, 2004, 143-144). Pero, en todo caso, para él el paisaje sólo se entiende como representación pictórica o poética, como obra de arte, y su pensamiento influyó directamente en muchos de los pintores paisajistas románticos. Sin duda uno de los que mejor representa su concepción idealista y romántica del arte fue el paisajista Caspar David Friedrich (17741840), que lo expresaba elocuentemente en los siguientes términos: El pintor -decía- no debe pintar meramente lo que ve ante sí, sino también lo que ve en sí. Y también: Cierra el ojo corporal para que veas primero tu pintura con el ojo del espíritu. Entonces deja salir a la luz lo que viste en la oscuridad, para que pueda ejercer su efecto sobre los otros, del exterior al interior ${ }^{5}$. Y quizás aún de forma más clara lo hacía su discípulo Carl Gustav Carus (17891869) al intentar definir la finalidad y significado de la pintura de paisaje en particular:

...cualquier arte que imita algo actúa sobre nosotros de dos formas; una en virtud de la naturaleza del objeto reproducido, cuyos rasgos peculiares nos afectarán en la imagen de forma similar a como lo hagan en la Naturaleza; y luego, además, como creación del espíritu humano, que eleva sobre lo vulgar al espíritu que le es afín dando apariencia verosímil a esas ideas (más o menos al modo en que el

4 Así la calificaba en el Programa de sistema más antiguo del idealismo alemán, un texto escrito hacia 1795 y en el que al parecer compartió autoría con Hegel y Hölderlin (VV.AA, 1994, 230)

5 Caspar David Friedrich: Declaraciones en la visita a una exposición (1830) (VV.AA, 1994, 94-98). 
mundo es, en su sentido más elevado, la forma de aparición de los pensamientos divinos) (Carus, 1992, 69).

\section{Johann Wofgang Goethe}

Bastante tiempo antes de que Schelling formulase su filosofía de la naturaleza, Goethe (y también Schiller y Harder) la concebía ya como una totalidad y una vivencia, como una fuerza productiva cuya capacidad creadora se podía comparar a la de un genio, y que sólo era accesible mediante la intuición sensible. Después de su viaje a Italia (1786-88) su concepción se hace más compleja y considera no sólo compatible sino necesaria una doble aproximación a la naturaleza: la científica, mediante la que estudia los objetos que la componen desarrollando para ello una morfología, y la artística, única capaz de captar la naturaleza como totalidad. Establece así cierta compatibilidad y armonía entre las exigencias de la razón analítica y las de la intuición sensible inmediata (Mas, 2004, 376-380). Pero, ¿en qué consistía el análisis que propugnaba? ¿Cómo entendía su empirismo?

En primer lugar, el procedimiento analítico de su método empírico se basa en lo que considera experimentos, que en realidad no pasan de ser múltiples observaciones detalladas de las formas y los fenómenos. Observaciones realizadas con los propios sentidos, sin introducir entre el investigador y el objeto ningún instrumento, ninguna lente que permita penetrar más allá de lo que se puede ver (Goethe, 2002, 50). Porque lo que se descubre por medio de instrumentos, forzando o «torturando»-como suele decir- a la naturaleza, no contribuye a su conocimiento, en tanto que nos aleja de lo real, de lo que se puede ver. Poco tiene que ver, por tanto, con el empirismo positivista, al que se oponía vigorosamente. Acusaba, por ejemplo, a Newton -a cuya teoría óptica de la descomposición de la luz se enfrentó contraponiéndole su teoría de los colores- de ligereza y de forzar los resultados de su hipótesis (Goethe, 2007, 244). Por el contrario, el suyo es un delicado empirismo que se identifica íntimamente con el objeto y se convierte así en una verdadera teoría (Goethe, 2002, 124).

Pero no todo el que mira ve. Para que la mirada sea eficaz los ojos del espíritu y los ojos del cuerpo deben actuar en una constante y viviente conexión, porque de otro modo se corre el peligro de mirar y, sin embargo, no captar lo que se ve (Goethe, 2007, 98). Por eso el ojo científico debe de haberse formado en el conocimiento, porque sólo se ve lo que conocemos. Es necesaria una enérgica ejercitación del ojo, y hay que aprender primero para preguntar después (Goethe, 2009, 185). Por otra parte, la mirada del científico debe ser desapasionada y atenta; al auténtico botánico no debe conmoverle ni la belleza ni la utilidad de las plantas, debe analizar su formación, su relación con el resto del reino vegetal (Goethe, 2002, 58 y 130).

El conocimiento científico debe proceder, sobre todo, de la propia naturaleza, que es sin duda alguna el único libro que posee gran valor en cada una de sus páginas (Goethe, 2009, 218). Las síntesis, las hipótesis, no carecen del todo de valor. En su concepción científica el análisis y la síntesis aparecen como complementarios. Las síntesis aparecen como hipótesis previas y también al final del análisis, como recomposición de lo separado. Las síntesis suponen la teoría y se relaciona con el mundo de las ideas y no suele estar de acuerdo con los experimentos realizados con los objetos reales. En la naturaleza, que constituye en sí una síntesis, el análisis de sus partes sólo permiten que nos hagamos una idea del conjunto, 
porque el «todo» es más que la suma de las partes (Hofmann, 2008, 42); el todo es la idea de la naturaleza. Cuanto más sepamos de las partes, más nos aproximaremos al conocimiento del todo, pero por esa vía la idea de la totalidad es inalcanzable. La naturaleza-que incluye categorías como la armonía y la belleza- está presente en todos sus componentes (principio fundamental del hermetismo) y en la relación entre los mismos, y sólo puede ser percibida espiritualmente, intuitivamente.

Uno de los conceptos más importantes de la concepción goethiana de la ciencia es el de fenómeno primigenio. Los fenómenos son los hechos que pueden observarse directamente en la naturaleza, empíricamente, y que la ciencia, mediante los experimentos, puede convertir en fenómenos científicos cuando descubre más o menos su secuencia. Tras la realización de todas las experiencias y experimentos obtendríamos el fenómeno puro. Los llamamos fenómenos primigenios, porque no hay nada que se manifieste por encima de ellos, y son en cambio enteramente adecuados para bajar peldaño a peldaño, igual que subimos antes, desde ellos hasta el caso más común de la experiencia cotidiana (Goethe, 2002, 189). Constituyen el límite de la ciencia porque son manifestaciones de la divinidad, de lo desconocido que sólo podemos adivinar, intuir.

En resumen, la concepción científica de Goethe se enmarca dentro de un idealismo neoplatónico con herencias del hermetismo, la Cábala, la alquimia y el vitalismo (Sánchez Meca, Goethe, 2007, XXI). Ahora bien, ¿cómo influían sus planteamientos científicos en su concepto de paisaje? ¿Qué era para él el paisaje?

Fue él quien, antes que el propio Humboldt, le dio al término un doble sentido, el pictórico que ya venía teniendo, y el de fragmento de la naturaleza que se muestra a la visión (Arnaldo, 2008, 15); que no es, sin embargo, la parte física de la naturaleza, sino su imagen, su representación, aunque ésta no tiene porque adoptar la forma de obra de arte, como ocurría en Shelling. Cualquier observador se forma una imagen de un fragmento de la naturaleza. De hecho ese es el lenguaje de la naturaleza; si el hombre se expresa con palabras la naturaleza lo hace con imágenes, es decir, con paisajes.

Por eso la lectura del paisaje es a la vez la lectura de la naturaleza y de nuevo ello exige de la instrucción de la mirada, una educación más relacionada ahora con el arte. El atento ojo desapasionado capaz de reconocer con claridad los objetos de la naturaleza, debe asimismo estar preparado para captar en ciertos momentos la totalidad de la naturaleza más allá de los objetos concretos que componen el paisaje:

«Faltan palabras para expresar la vaporosa claridad que flotaba en torno a las costas cuando arribamos a Palermo la más hermosa de las tardes. La pureza de los contornos, la suavidad del conjunto, los contrastes de los tonos, la armonía de cielo, mar y tierra. Quien ha visto esto lo conserva para siempre. Ahora por primera vez comprendo a Claudio de Lorena y tengo la esperanza de que cuando me halle de regreso en el norte también yo sabré sacar a la luz desde el fondo de mi alma las imágenes de esta feliz estancia» (Goethe, 2009, 132, 185, 253).

Se adelantaba así, por tanto, al pintor romántico Caspar David Friedrich.

Sólo desde el arte es posible alcanzar esa naturaleza total, presente en los objetos que la componen, pero que no se revela a cualquier observador. Exige de la intuición sensible, de 
la comprensión empática, de la capacidad de aperçu como él la denominaba y que definía como un golpe de sentimiento que permitía la revelación de nuevas certidumbres y que tenían un efecto renovador en el sujeto (Arnaldo, 2008, 28). Contemplar la belleza, que es un fenómeno primigenio (Goethe, 2002, 190) tras el cual están Dios y la Naturaleza en su totalidad. Un aperçu sólo alcanzable por quien sabe mirar el paisaje como artista, incluso como artista plástico. Porque el aperçu se manifiesta en la contemplación, pero para captar y retener esa imagen resulta imprescindible recurrir al dibujo o la pintura. De ahí el gran interés que Goethe dedicó toda su vida a educar su mano de dibujante al mismo tiempo que su ojo. A pesar de reconocer su falta de talento en esta faceta artística (Goethe, 2009, 192), con la constancia del cazador de paisajes (como el mismo se consideraba) y el esfuerzo de un permanente aprendiz, recogió en sus dibujos las visiones de sus vivencias, de sus experiencias de la naturaleza, a veces meros testimonios de objetos interesantes, otras verdaderas representaciones de sus aperçus

Como representación de la naturaleza, como imagen, el paisaje en Goethe es, por tanto, un paisaje cuadro, una vista, estuviese ésta o no en una pintura o dibujo. La visión del paisaje se realiza desde un punto, un mirador bien elegido en función del panorama que ofrece o de la incidencia de la luz a cierta hora del día. Como ha señalado Besse $(2010,88)$, desde allí la mirada es intencional y selectiva, destaca los elementos y compone la pintura, aunque ésta no se lleve al lienzo. En definitiva, la concepción del paisaje en Goethe está en perfecta consonancia con su idea de la naturaleza; constituye una aproximación desde el arte complementaria a la que propone desde la ciencia.

\section{CIENCIA, NATURALEZA Y PAISAJE EN ALEXANDER VON HUMBOLDT}

Absolutamente empirista en el sentido fuerte del término, se separa claramente de Goethe en el terreno propiamente científico y utiliza sofisticados instrumentos a los que considera «nuevos órganos» de observación y experimentación. Durante su viaje a la América tropical Humboldt y su compañero Bonpland cargaron con un pesado equipo que incluía los más modernos instrumentos del momento: telescopio acromático, anteojo con micrómetro (para seguir eclipses), cronómetro de precisión (para calcular la longitud), sextantes, un teodolito, un horizonte artificial, un cuadrante, un grafómetro, brújula-clinómetro, brújula de declinación, un eudiómetro (que calculaba la proporción de oxigeno en el aire), dos higrómetros, varios barómetros, termómetros, electrómetros, hidrómetros, aerómetros, magnetómetros, eudiómetros, un microscopio compuesto y un cianómetro (para medir la intensidad del azul del cielo) (Herrera Piqué, 2010, 40-41). Un completísimo equipo que les permitió realizar multitud de observaciones sistemáticas de carácter astronómico, meteorológico, geográfico, geológico, botánico y químico, que combinadas y comparadas les proporcionarían el andamiaje fundamental de su trabajo científico. Su empirismo es además racionalista, al modo que lo entendían también los ilustrados franceses (Diderot, 1992, 21), es decir, apoyado en hipótesis previas que necesitan ser confirmadas por la experiencia (Humboldt, 2005 a, t. I, 74). Ese constituye, a su entender, el método científico seguro para conseguir avanzar con paso firme en el conocimiento de la realidad, superando los estadios previos de imaginación especulativa y adivinación que predominaban cuando buena parte de las preguntas quedaban sin respuesta: 
«Desde el punto en que el hombre interroga á la naturaleza, no ya en calidad de mero y pasivo observador, sino creando él mismo fenómenos bajo condiciones determinadas; y desde que compila y anota los hechos para estender la investigación mas allá del corto período de duracion de su existencia individual, la Filosofia de la Naturaleza se despoja de las formas vagas y poéticas propias de su origen, adopta un carácter más severo, compulsa el valor de las observaciones, y ya no se entrega a la adivinación como antes, sino a la combinación y al raciocinio» (Humboldt, 2005 a, t. I, 18-19) ${ }^{6}$.

Podría, por tanto, pensarse que Humboldt habría resistido al influjo de la filosofía idealista de la naturaleza. Es cierto que en su colaboración con la revista de Schiller (Die Hören) en 1795 titulada La fuerza vital o el genio de Rodas defendió posiciones vitalistas muy próximas a las de Goethe. Sin embargo, apenas dos años después, se desmarcaba definitivamente de ellas a través de su Essais sur la fibre musculaire et nerveuse en el que hacía referencia a sus experimentos sobre el galvanismo y en el que renunciaba a la idea de fuerza vital en tanto que especulación. El genio de Rodas y su valoración crítica volvió a ser incluido en la tercera edición de los Cuadros de la Naturaleza, concluyendo en términos absolutamente materialistas:

«La descripción física del mundo debe mostrar que todos los materiales de que la armazón de los seres vivos está compuesta, se encuentran también en la corteza inorgánica de la tierra: que los vegetales y los animales se hallan sometidos a las mismas fuerzas que rigen la materia bruta, señalando en las combinaciones o descomposiciones de ésta, la acción de los mismos agentes que dan a los tejidos orgánicos sus formas y sus propiedades; solo que entonces obran dichas fuerzas bajo condiciones poco conocidas que se designan con el vago nombre de 'fenómenos vitales' y que se han agrupado sistemáticamente según analogías más o menos acertadas» (Humboldt, 2003, 391)

Sin embargo, su distanciamiento de la filosofía de la naturaleza está muy lejos de ser una verdadera ruptura. Todo lo contrario; si bien rechazaba los excesos especulativos e idealistas, admitía que ciertos planteamientos racionalistas especulativos bien fundamentados podían ser compatibles con el enfoque propiamente científico:

«Concepciones del universo fundadas únicamente sobre la razón ó sobre los principios de la filosofía especulativa, asignarían sin duda a la ciencia del Cosmos fin mas noble y elevado. Lejos de mi la idea de vituperar esfuerzos que yo no he intentado, y de vituperarlos por el solo motivo de que su éxito haya sido hasta ahora muy problemático. Contra la voluntad y los consejos de los profundos y poderosos pensadores que han dado nueva vida a especulaciones ya familiares en la antigüedad, los sistemas de filosofía de la Naturaleza han alejado los ánimos por cierto tiempo en nuestra patria de los graves estudios matemáticos y físicos.

6 En las citas de esta edición de Cosmos se ha respetado la ortografía original. 
La embriaguez de supuestas conquistas ya alcanzadas; un lenguaje nuevo caprichosamente simbólico; la predilección por fórmulas de racionalismo escolástico tan severas como jamás se conocieron ni aun en la edad media, han caracterizado, por el abuso que ha hecho de sus fuerzas una juventud generosa, las efímeras saturnales de una ciencia puramente ideal de la Naturaleza. Abuso de la fuerza, repito, porque talentos superiores consagrados de consuno á los estudios filosóficos y á las ciencias de observación, han permanecido estraños a aquellas saturnales. Los resultados obtenidos por investigaciones profundas en la via de la experiencia no pueden ser contradictorios con la verdadera filosofía de la Naturaleza». (Humboldt, 2005 a, t. I, 75-76).

\section{La concepción de la naturaleza en Humboldt}

Ahora bien, ¿cuál es la verdadera filosofía de la naturaleza y qué aspectos son realmente compatibles con su discurso científico? En primer lugar, para Humboldt la naturaleza aparece como un todo, como la unidad sobre la diversidad de sus elementos. Esta concepción holista, que ya hemos visto en la filosofía de la naturaleza idealista alemana, es, sin embargo, común en científicos y filósofos materialistas. Fue sostenida, por ejemplo, por Buffon, considerado el primer biólogo materialista (Flórez Miguel, 2010, 61), y de él la tomó también Diderot (Minguet, 2003, 79). En ciertas partes de su discurso Humboldt parece darle el mismo sentido que éstos le daban: la unidad y totalidad de la naturaleza se manifiesta sobre todo en el encadenamiento causal que explican los fenómenos, en la interrelación de las fuerzas. De hecho, descubrir estas concatenaciones era su verdadero objetivo científico, como confiaba a su amigo Freisesleben en una carta enviada desde el Pizarro justo antes de zarpar hacia el Nuevo Mundo el día 5 de junio de 1799:

«Recolectaré plantas y fósiles y realizaré observaciones astronómicas. Pero éste no es el objetivo principal de mi expedición. Intentaré descubrir cómo interaccionan entre sí las fuerzas de la naturaleza y cómo influye el ambiente geográfico en la vida animal y vegetal. En otras palabras, he de buscar la unidad de la naturaleza» (citado por Botting, 1995, p. 57).

Un objetivo que aparece repetido multitud de veces en su obra y en su correspondencia, y que constituye el fundamento de su testamento científico, expresado en el propio título: Cosmos.

«Para que esta obra sea digna de la bellisima espresion de Cosmos, que significa órden en el Universo y magneficencia en el órden, debe abrazar y describir el gran Todo, clasificar y coordinar los fenómenos, penetrar el mecanismo y el juego de las fuerzas que los producen, y pintar en fin, con animado estilo, una imagen vivificante de la realidad» (Humboldt, 2005 a, t. I, 80).

Dejemos para más adelante el tratamiento de esas referencias pictóricas y estéticas y mantengamos la atención sobre esa concepción unitaria y de totalidad de la naturaleza, a la 
que habría que añadir las categorías de orden y armonía. En este sentido, dicha concepción muestra una gran ambigüedad, que se manifiesta en afirmaciones muy próximas al idealismo de la Naturphilosophie

«Racionalmente considerada la Naturaleza, es decir, sometida a la elaboración de la inteligencia, no es más que la unidad en la diversidad de los fenómenos, la armonía entre todas las cosas creadas, desemejantes en su forma, en su constitución propia y en las fuerzas que las animan; el Todo penetrado por un soplo de vida. El resultado más importante del estudio racional de la naturaleza es la comprension de la unidad y de la armonía en medio del inmenso agregado de cosas y de fuerzas» (Humboldt, 2005 a, t. I, 19).

Parece predominar, en el fondo de su pensamiento, la idea panteísta de naturaleza creadora que defendió Schelling, a quien cita en Cosmos para mostrarle su acuerdo:

«La Naturaleza, dice Schelling en su poético discurso sobre las artes, no es una masa inerte, antes bien personifica, para el que llega a penetrar en su sublime grandeza, la fuerza creadora del Universo, fuente primitiva, eterna, que obra incesantemente, y da nacimiento en su propio seno á cuanto existe y alternativamente perece y renace» (Humboldt, 2005, t. I, 52)

En cuanto al segundo de los aspectos de su concepción de la naturaleza, el de la «armonía», entendida tanto en el orden universal que reina en el Todo como en la integración del hombre y la naturaleza, de nuevo constituye una idea compartida entre idealistas y materialistas ilustrados. Ciertamente, en sus trabajos empíricos, Humboldt había ido derivando hacia algunas concepciones que al menos cuestionaban la eterna armonía en la evolución de la naturaleza. El abandono del neptunismo de Werner en el que se había formado -con gran disgusto de Goethe que siguió fiel a tales ideas- y la aceptación del plutonismo, suponía -o debería haber supuesto como señala Minguet $(2003,88)$ - un cierto cuestionamiento de esa armonía evolutiva. El estudio de numerosos volcanes en los Andes y los frecuentes terremotos que sintió en las tierras tropicales, o los estragos que descubrió de otros recientes, hicieron desvanecerse la imagen de una lenta, tranquila y continua emergencia de los continentes desde los océanos. Aceptó entonces las teorías más violentas y catastróficas que proponían una evolución no uniforme sino caracterizada por saltos bruscos y repentinos. Por otra parte, en su viaje a la América tropical pudo comprobar como las relaciones del hombre con la naturaleza tampoco resultaba tan armónica como se creía en el Viejo Mundo de su época, dominada por una sustitución ordenada de la vegetación natural por plantas útiles. En muchas partes del Nuevo Mundo era la naturaleza la que dominaba totalmente; se imponía al hombre hasta tal punto que en ocasiones le excluía de lugares llenos de vida, como sucedía en el entorno del canal natural Casiquiare que une el río Negro, perteneciente a la cuenca del Amazonas, con el Orinoco. La descripción de los nueve días que navegaron por el canal nos muestra lo penoso de la travesía: devorados por los mosquitos en una selva enseñoreada por las fieras salvajes, tan densa y húmeda que apenas podían acercarse a la orilla y encender fuego (Humboldt, 2005 b, 340-351) 
A pesar de todo, a pesar de la hostilidad que con frecuencia mostraba la naturaleza para con el hombre, de sus bruscos e imprevistos comportamientos que aparentemente ocurrían tan desordenadamente, Humboldt jamás renunció a la armonía del Cosmos, aquella que se percibía en el Universo, ya descrita por Copérnico y Kepler (Humboldt, 2005 a, t. II, 388 y 399), que no sólo se manifestaba en el cielo, sino en el conjunto del Cosmos en el que todos sus elementos se interrelacionaban armónicamente.

Un tercer aspecto que también parece contradictorio con una concepción empírica, materialista y positiva de la ciencia, es la aceptación de la vieja idea de que la naturaleza ejercía un influjo positivo en la moralidad e inteligencia de los pueblos. No se trata, en absoluto, de una idea original suya, ni tampoco procedente únicamente de los filósofos idealistas alemanes. Es fácil reconocer en ella una cierta influencia rousseauniana, de aquél papel pedagógico otorgado a la naturaleza en cuyo entorno era fácil reforzar los valores de solidaridad y justicia. Y quizás también se puede percibir en la formulación humboldtiana un cierto eco determinista, aunque ciertamente matizado:

«Al presentar en una misma obra los groseros monumentos de los pueblos indígenas de América y los sitios pintorescos del país montuoso que han habitado, creo reunir objetos cuyas relaciones no han escapado a la sagacidad de los que se dedican al estudio filosófico del espíritu humano. Por más que las costumbres de las naciones, el desenvolvimiento de sus facultades intelectuales, el carácter particular de sus obras impreso, dependen a la vez de infinitas causas que no son puramente locales, no puede desconocerse que el clima, la configuración del suelo, la fisonomía de los vegetales, el aspecto de una naturaleza risueña o salvaje influyen en el progreso de las artes y estilo que distingue sus producciones; influencia más sensible a medida que el hombre se encuentra más apartado de la civilización» (Humboldt, 2010, 53).

\section{Ciencia y estética en la gnoseología de la naturaleza en Humboldt}

Todos estos aspectos: unidad, totalidad, armonía e influjo sobre el hombre, juegan un papel fundamental en sus objetivos científicos. No se trata sólo de descubrir las concatenaciones de los diversos elementos de la naturaleza, de comprender su unidad por encima de la diversidad, sino también de reconocer el influjo que ésta tiene en la sensibilidad del hombre. Y es aquí donde el aspecto estético y el paisaje entendido desde esta óptica, comienzan a tomar relevancia. No es sin embargo un aspecto que se encuentra al final del proceso de conocimiento, sino más bien al principio. En la primera parte de la introducción de Cosmos, Humboldt califica como «primer goce» al influjo que experimenta cualquier hombre por el mero contacto con la naturaleza, percibiendo su efecto positivo y tranquilizador e intuyendo la unidad y armonía de la misma. Desde ese primer goce se alcanza el segundo cuando se trata de un paisaje vivido o evocado junto a fuertes vivencias, y el tercero cuando junto con el encanto producido por la sencilla contemplación de la Naturaleza en el contacto del hombre con el mundo esterior, viene á unirse el goce que emana del conocimiento de las leyes y del encadenamiento mútuo de aquellos fenómenos (Humboldt, 2005 a, t. I, 31). En realidad, la incorporación del tercer goce puede entenderse igualmente como proceso de instrucción del 
hombre contemporáneo, o como avance histórico del conocimiento según el cual las comunidades primitivas, que sólo presentían la armonía y orden del universo, evolucionan a través de observaciones bien fundadas hasta alcanzar evidencias y verdades positivas, desterrando entonces la adivinación y la mitología.

Esta forma de presentación del proceso de conocimiento como una línea que conduce del sentimiento estético (dominado por la intuición) al saber científico (dominado por la experiencia empírico racional), sobre la que ya llamó la atención Farinelli $(2009,44)$, tiene, a mi modo de ver, gran importancia para comprender la concepción humboldtiana de la naturaleza y el paisaje. En primer lugar, reparemos en que Humboldt denomina a esos niveles «goces», es decir, formas de disfrutar la naturaleza (una idea muy próxima a Goethe). Con ello se incorpora al debate que venían imponiendo algunos filósofos y poetas alemanes (como Schiller), que criticaban el trabajo científico en tanto que destructor del encanto de la naturaleza:

«Voy á refutar, y de ello casi me pesa, cierto temor que tiene al parecer su origen en una mirada limitada, ó en no se que muelle y débil sentimentalismo del alma: hablo del temor que algunos manifiestas de que la Naturaleza pierda su encanto y el prestigio de su mágico poder, á proporción que vayamos penetrando sus secretos, comprendiendo el mecanismo de los movimientos celestes, y calculando numéricamente la intensidad de las fuerzas. Cierto que estas no ejercen sobre nosotros lo que propiamente puede llamarse un poder mágico, sino en tanto que su accion, envuelta entre misterios y tinieblas, se halla colocada fuera de todas las condiciones que ha podido alcazar la esperiencia; y por lo mismo, el efecto de semejante poder es conmover nuestra imaginacion; pero cabalmente no debe evocarse con preferencia esta facultad del alma, cuando se trata de las laboriosas y prolijas observaciones que tienen por objeto el conocimiento de las leyes mas grandes y admirables del Universo...» (Humboldt, 2005 a, t. I, 34)

Por lo tanto, si el primer goce, la contemplación libre de la naturaleza excita la imaginación sin límites, el tercero, que contribuye a poner límites a la imaginación, sirve, sin embargo, para ampliar los horizontes del conocimiento. Ahora bien, para poder transmitir los conocimientos que procuren ese tercer goce es necesario quitar-como ya había dicho Goethe- los andamios que sirvieron para construir el edificio del conocimiento, eliminar todos aquellos laboriosos trabajos de observación imprescindibles para la fundamentación científica, que además de tediosos distraen del verdadero propósito: la comprensión de la unidad, del orden de la naturaleza y de los beneficios de la aplicación de los conocimientos científicos. Humboldt se propone así en Cosmos presentar una síntesis que responda a esos objetivos principales. Por eso esa magna obra no puede entenderse como una mera enciclopedia:

«No debemos, por tanto, confundir la física del mundo con esas Enciclopedias de las ciencias naturales publicadas hasta ahora, de tan vago título como mal trazados límites. En la obra que nos ocupa no consideramos los hechos parciales sino en sus relaciones con el todo; pues cuanto mas elevado es este punto de mira, mas 
reclama la exposicion de nuestra ciencia un método propio, peculiar, y un estilo pintoresco y animado» (Humboldt, 2005 a, t. I, 52).

¿No recuerdan esas «relaciones con el todo» a las que Schelling otorgaba a los intermediarios? En todo caso, no está tan claro que, como afirma Farinelli $(2009,44)$, en esa síntesis Humboldt abandonase ya el nivel estético y la impresión sentimental, para convertirse en plenamente científica. Desde muy temprano su concepción sobre la ciencia parecía ya albergar un lugar para la estética. En una carta enviada a Schiller en 1794, respondiendo a la llamada de éste para que participase en su revista Die Hören, resumía su programa científico y reconocía ya esa íntima relación:

«La manera como se ha tratado la historia de la naturaleza hasta el presente, ha sido una manera en la que no se toma en cuenta más que las diferencias de la forma, en la que se estudiaba la fisonomía de las plantas y de los animales, en la que se confundía incluso, la enseñanza de las características, la enseñanza de la identificación, con la ciencia sagrada, a tal punto que nuestra ciencia botánica por ejemplo, en el mejor de los casos, no podía ser nada más que un objeto de mediación de mentes especulativas.

Pero vos sentís al igual que yo, que es menester buscar algo más elevado, que es ese algo lo que hay que redescubrir; porque Aristóteles y Plinio, quienes en su descripción de la naturaleza incluían a un mismo tiempo el sentido estético y la educación artística del hombre, tenían ciertamente puntos de vista mucho más amplios que nuestros miserables archivistas Registratoren de la naturaleza» (citado por Minguet, 2003, 92).

Mantuvo esa concepción hasta su muerte, y así queda reflejada en Cosmos. Ahora bien, ¿de qué manera incorpora la estética al trabajo científico y qué efectos tiene sobre él? El estilo literario y la selección ordenada de materiales jugaran en ese sentido un papel destacado:

«Grandes dificultades ofrece la composicion de una obra de este género, si al mérito intrínsico científico ha de reunir el de la forma literaria; porque se trata de llevar el órden y la luz á la inmensa y rica copia de materiales que se ofrecen al pensamiento, sin despojar no obstante a los cuadros de la Naturaleza del soplo vivificador que los anima» (Humboldt, 2005 a, t. I, Prefacio, XI-XII).

Un estilo vivaz y pintoresco que aplicará, sobre todo, a las descripciones de paisajes, que se convierten así en representaciones - a veces de gran belleza plástica- dominadas por la estética romántica, por lo pintoresco, lo infinito, lo sublime y lo melancólico. Destaca sobre todo en ciertos pasajes de obras como los Cuadros de la Naturaleza, en la descripción de los Llanos de Venezuela, por ejemplo, en donde introduce un estilo descriptivo-narrativo -sobre el que ya llamó la atención Josefina Gómez Mendoza (2008, 17) - que le permite ir dando cuenta de los cambios fisionómicos que se van produciendo desde la sequía a la época de lluvias, sin olvidarse de narrar la formación de los tornados, las engañosas imágenes producidas 
por la refracción de la luz o la repentina reanimación de serpientes acuáticas y cocodrilos tras el primer turbión (Humboldt, 2003, 57-60). En ocasiones, no obstante, se detiene cautivado ante un paisaje cuadro y sus descripciones recuerdan mucho a las de Goethe. Así sucede en el cuadro dedicado a las Cataratas del Orinoco:

«Hay allí un punto desde el cual se descubre un horizonte maravilloso. Abraza la vista una superficie de dos leguas cubierta de espuma. Del centro de las olas levántanse negras rocas, como de hierro, que parecen torres ya arruinadas. Cada isla, cada piedra, ostenta gran número de árboles de vigorosa producción; espesa nube flota constantemente sobre el cristal de las aguas y a través de este vapor espumoso asoman las altas copas de las palmeras mauritia. Cuando ya a la tarde los ardientes rayos del sol vienen a quebrarse en la húmeda niebla, estos efectos de luz producen un espectáculo mágico. Arcos coloreados aparecen y desaparecen sucesivamente y sus imágenes vaporosas se mecen a impulso de los vientos». (Humboldt, 2003, 190)

¿Encierran estas descripciones golpes de sentimiento similares a los que Goethe denominaba aperçu? ¿Juega el paisaje para Humboldt un papel similar, es decir, revelador de fenómenos primigenios o de lo absoluto? En ocasiones podría parecernos que sí:

«Al iluminarse la extremidad de la planicie con el rápido nacer o ponerse de brillantes astros, o reflejarse su temblorosa luz sobre las capas inferiores de los vapores ondulosos, créese tener ante los ojos un océano inmenso. Como este, llenan también las estepas el alma del sentimiento de lo infinito; desátanla de las impresiones materiales que producen los espacios limitados y la elevan a las más altas inspiraciones. Pero todo lo dulce que es contemplar el claro espejo del mar, rizado por las inquietas y espumosas olas, lo tiene de frío y muerto la perspectiva del desierto, semejante a la que mostraría la desnuda corteza de un planeta devastado» (Humboldt, 2003, 43-44).

También se podría pensar que se trata de impresiones comunes a cualquier observador sensible. Pero no olvidemos que es a través del paisaje como, según Humboldt, se alcanza el primer goce descrito en la introducción de Cosmos, es decir, la intuición, ante la belleza, de la unidad y la armonía de la naturaleza, y ello aparentemente se encontraría muy próximo a la aperçu goethiana, se consideren o no esos fenómenos como primigenios. ¿Se incorporaron dichas impresiones a su discurso científico? En principio parecen formar parte del conocimiento precientífico (del primer goce). Álvarez López $(1959,362)$ afirma que más bien Humboldt mantiene bien separada la realidad material objetiva de los sentimientos que ésta puede provocar en el observador, dos aspectos que no podrían disociarse en el idealismo:

«Temeraria asaz es la tentativa de descomponer en sus diversos elementos la magia del mundo físico; porque el gran carácter de un paisage, como de toda escena imponente de la Naturaleza, depende de la simultaneidad de las ideas y de los sentimientos escitados en el observador. Pudieramos decir que el poder de la 
Naturaleza se revela en la conexion de las impresiones, en la unidad de emociones y de efectos producidos en cierto modo de una sola vez; y así, cuando se quieren indicar sus fuentes parciales, es preciso descender por medio de la análisis á la individualidad de las formas y á la diversidad de las fuerzas» (Humboldt, 2005 a, t. I, 22).

Pero la cosa, a mi modo de ver, no está tan clara. No olvidemos que Schelling también le concedía un lugar a la investigación empírica. Desde luego, no se trata simplemente de una cuestión de estilo -como ha afirmado Minguet (2003, 82-83)-, por más que éste juegue ciertamente un papel destacado. En efecto, descripciones pintorescas, representaciones paisajísticas literarias que rezuman sensibilidad romántica y que están presentes, además de en los Cuadros, en buena parte de los escritos que componen el Viaje a las regiones equinocciales del Nuevo Continente, la Geografía de las plantas, Vistas de las Cordilleras y monumentos de los pueblos indígenas de América y en menor medida en otras obras, han servido de argumento a quienes ven la concepción paisajística humboldtiana como precursora de la actual. $\mathrm{Y}$ en cierto modo su manera de describir nos puede resultar familiar, aunque no tanto por su relación con la Geografía propiamente dicha, sino más bien con algunas guías de viaje. Así lo entendía el propio Humboldt, que en numerosas ocasiones se dirige a «el viajero»:

«Súbitamente arrebatado a todas las riquezas de la vida orgánica, sorpréndese el viajero al penetrar en estos espacios sin árboles, que apenas le ofrecen huellas de vegetación» (Humboldt, 2003, 43).

No se trata siquiera de un estilo original y exclusivo; de hecho lo había aprendido de otros, como confiesa en sus numerosos reconocimientos a su malogrado amigo «y maestro» Georg Forster. Con él había realizado un viaje en 1790 por el bajo Rhin e Inglaterra, que Forster narró en un nuevo libro (Ansichten vom Niederrhein) calificado por Amando Melón como «uno de los mejores relatos de viaje de todas las lenguas y de todos los tiempos» (Melón, 1960, 35). Con dicho «estilo vivaz» pretendía Humboldt conectar con la fibra sensible de los jóvenes, animar en ellos el espíritu de aventura y la curiosidad científica al descubrirles el paisaje vegetal exótico de los trópicos. Después de todo, eso era lo que le había impulsado a él:

«Si se me permite recurrir á los mas antiguos recuerdos de mi juventud, é indicar lo que sirvió de cebo para inspirarme el incontrastable deseo de visitar las regiones tropicales, citaré principalmente las descripciones pintorescas de las islas del Mar del Sur, por Jorge Forster; los cuadros de Hodges que representan las orillas del Ganges, en la casa de Warren Hastings de Londres; y un drago colosal que ví en el antiguo invernáculo del jardín botánico de Berlin» (Humboldt, 2005 a, t. II, Introducción V) ${ }^{7}$

7 En este sentido Humboldt tuvo un importante éxito: cerca de 200 alemanes (geólogos, geógrafos, historiadores, artistas) siguieron las huellas de su viaje (Gómez Acosta, 2010, 305-306). Y a ellos habría que añadir los ingleses y norteamericanos, que escribieron sus propias guías de viaje en las que es posible constatar las continuas referencias al naturalista prusiano y sus mismos recorridos (Mörner, 1999, 9). 
Excitar ese gusto, incentivar ese interés, se encuentra, por tanto, dentro de sus objetivos, que parecen surgidos de un afán pedagógico casi explícito:

«... todos estos objetos que están reunidos en el «Cuadro de la naturaleza», sin duda son capaces de ocupar en forma múltiple la fantasía y formar en ella nuevos conceptos y conclusiones. Visto de este modo, podría provocar a un mismo tiempo una descripción de la naturaleza de los trópicos, el deseo del saber y la fuerza de la imaginación, e incitar, aun aquellas para el estudio de la física, a los cuales hasta entonces había sido cerrado este manantial del rico goce intelectual» (Humboldt, 1985, Cuadro, parte I)

Para cumplir ese objetivo la literatura de su «estilo vivaz» no era suficiente. Humboldt conocía ya el poder de la imagen, recurso que en su tiempo se limitaba a la pintura y el grabado. Por eso explora en la historia de la pintura de paisajes, a la que dedica todo un capítulo de la primera parte del tomo segundo de Cosmos. Lo titula «Influencia de la pintura de países en el estudio de la naturaleza», y, como en él se indica, pretende mostrar como las artes, plásticas en este caso, pueden contribuir al conocimiento de la fisonomía de las plantas de los diferentes lugares de la tierra, adquirir la aficion á viajes lejanos, y alimentar en nosotros, de una manera tan instructiva como agradable, el deseo de ponernos en comunicacion con la naturaleza libre (Humboldt, 2005 a, t. II, 84). En su propia obra trata de cuidar con gran esmero las ilustraciones. Era buen dibujante; había recibido en su formación clases de dibujo y mantuvo siempre la práctica y el aprendizaje de nuevas técnicas. En Londres conoció en 1790 a William Gilpin, que acababa de publicar dos narraciones de viajes ilustradas con sus propias acuarelas, resaltando la belleza pintoresca de algunos paisajes ingleses y escoceses y proporcionando sugerentes ideas sobre las técnicas de abocetar paisajes al natural (Sosa Henríquez y Castro Morales, 2008, 156). A lo largo de su viaje a América reunió una gran cantidad de bocetos realizados en el campo, muchos de ellos de paisajes. A la vuelta quiso publicar algunos en un libro que acabó titulando Vistas de las Cordilleras y monumentos de los pueblos indígenas de América (Humboldt, 2010), que contenía 69 ilustraciones comentadas. Dado que no se consideraba capaz de perfeccionar sus propios bocetos, tuvo que recurrir a diferentes pintores (Joseph Anton Koch, Gottlieb Schick, Wilhelm Friedrich Gmelin o Jean-Tomas Thibaut) que realizaron las verdaderas ilustraciones para las planchas de los grabados. El resultado, sin embargo, no satisfizo del todo al naturalista alemán, que justificaba las deficiencias por la torpeza de sus esbozos que sirvieron de modelo a los artistas (Humboldt, 2010, 32). Pero lo cierto es que a él no le gustaron las reelaboraciones de los artistas porque resultaban demasiado académicas y «europeas», desprovistas de la naturalidad y frescura originales (Verdú Schumann, 2008, 199). El problema de esos pintores, a los que por otra parte nada podía reprochar como artistas, era que nunca habían estado en América y no eran capaces de transferirles la emoción y vivacidad de la evocación. Los esbozos y sus propias indicaciones resultaban del todo insuficientes para suplir tales carencias:

«Estas magnificas regiones apenas han sido hasta ahora visitadas mas que por algunos viajeros no muy experimentados de antemano en las artes, y á los cuales no dejaban espacio ni vagar sus ocupaciones científicas para perfeccio- 
nar su talento de paisistas... Los artistas encargados de acompañar a las grandes expediciones enviadas por cuenta del Estado á aquellos paises, eran por lo comun escogidos al acaso, y no se tardaba en reconocer su insuficiencia» (Humboldt, 2005 a, t. II, 98).

Parece como si hubiese intuido las dificultades que habría de tener en encontrar pintores preparados para representar las escenas americanas. De ahí que cuando en 1803 redactó en el puerto de Guayaquil el primer bosquejo de sus Ideas para una geografía de las plantas más un cuadro de los países tropicales, incorporase una magnífica lámina en la que presentaba un perfil de la cordillera de los Andes a la altura del Chimborazo y del Cotopaxi, en el que introdujo en cada vertiente una forma diferente de representación: una esquemática, más propia de la información cartográfica, y la otra figurativa, en la que las plantas aparecían dibujadas (y luego pintadas) con gran precisión. Con esa parte figurativa pretendía estimular la inspiración artística y descubrir las nuevas formas vegetales a los pintores de paisaje ${ }^{8}$. Así lo describía y justificaba él mismo:

«El dibujo el cual yo mismo bosquejé en Guayaquil, fue continuado en París por un gran artista, el señor Schoenberger. Para dar a este trabajo aquella perfección indispensable para ser grabado en cobre, dio el señor Turpin los últimos toques. Pero un cuadro que está sujeto a las escalas laterales que lleva en su marco, para apreciar el perfil que representa, no puede lograr de por sí una gran expresión artística-pintoresca; porque todo lo que exige exactitud geométrica es contrario a este efecto. Se pensaba que la vegetación sólo debería aparecer como masa y por lo mismo, como en los planos militares, apenas indicada. Pero sin embargo he creído que me podría permitir destacar en la llanura (al mismo tiempo como primer plano), la espesura de los plátanos con sus hojas suaves y los troncos altos de las palmas más concretamente. Se ve luego cómo los plantíos de plátano y las palmas de abanico se pierden lentamente entre árboles de follaje pequeño; éstos a su vez en un rastrojo más pequeño todavía y el rastrojo por fin se pierde en los pajonales. Las hierbas llegan hasta donde la compacta cubierta del suelo, cada vez más delgada, se extiende sobre las cumbres... Seguramente hubiera sido de mejor gusto para el conjunto del cuadro, sí no se hubiera escrito ningún número, ni ninguna observación alrededor de los contornos de los Andes. Pero en esta presentación geográfica se pretendía presentar a un mismo tiempo dos condiciones, frecuentemente excluyentes entre sí: exactitud y efecto pintoresco. Hasta dónde lo hemos logrado, lo resolverá el público». (Humboldt, 1985, Cuadro, parte 2a).

Es decir, si la literatura y la pintura contribuyen a la comprensión de la ciencia e incitan a la exploración y al trabajo científico, la ciencia, por su parte, podía igualmente contribuir a la

8 Como ha señalado Verdú Schumann (2008, 204-205), también en ello Humboldt tuvo éxito, si bien en este caso fue tardío. Sus indicaciones sobre las formas y estética de la pintura fueron recogidas por los pintores norteamericanos de la Escuela del Río Hudson en la segunda mitad del siglo XIX. Uno de sus representante más destacado, Frederic Edwin Church rehízo alguno de los dibujos de Humboldt y se especializo en paisajes de montañas y volcanes tropicales. 
mejora de la expresión artística, mostrándole las formas desconocidas y exóticas de la vegetación y su distribución altitudinal. Ahora bien, esa colaboración mutua entre la ciencia y el arte -meramente instrumental- no parece base suficiente para la renovación de su alianza, como reclamaba Goethe, en el sentido fuerte, es decir, sustancial. Sin embargo, Humboldt parece reconocer en algunas pinturas de paisaje -a las que lejos de exigir una fidelidad realista alaba su interpretación artística y romántica- esa alianza más estrecha:

«Si algo puede todavía esperar el arte, y si he creido conveniente indicar una via nueva para reanudar, con el pensamiento al menos, la antigua alianza de la ciencia, del arte y de la poesía, no por ello se menoscaba ni en un ápice la gloria de aquellos grandes maestros. En la pintura de paises, lo mismo que en todas las demás ramos del arte, hay que distinguir entre el elemento limitado que suministra la percepcion sensible, y la mies sin limites fecundada por la profunda sensibilidad y la poderosa imaginacion del artista» (Humboldt, 2005 a t. II, 99-100)

La pintura de paisaje no es ni debe ser una ilustración científica, ni siquiera tiene por que ser una imitación propiamente dicha de la naturaleza como se ha sugerido (Gómez Mendoza y Sanz Herráiz, 2010, 54). Humboldt asume así los cambios de pautas estéticas introducidos por el romanticismo; en primer lugar la superación del concepto de imitación en el arte; en segundo la superación hacia el infinito de la finitud de la forma (D’Angelo, 1999, 120-123 y 223). La pintura de paisaje está, por eso, en condiciones de representar la «totalidad» y la «unidad» de la naturaleza a partir de elementos concretos. Constituyen fuentes de excitación; su función es equiparable a la de la propia naturaleza; ejerce la misma influencia en el observador sensible que la propia contemplación de la naturaleza; ideas, por lo demás, bastante próximas a las de Schelling.

Tanto las representaciones literarias como pictóricas del paisaje enfatizan, por lo tanto, los aspectos sensibles y emotivos, aquellos que permiten al lector u observador conectar con lo no visible, con las categorías más elevadas de la naturaleza. Aspectos que dominan sobre los propiamente objetivos. Son representaciones subjetivas del paisaje, percepciones sensibles individuales que parecen poder reconocer verdades ocultas en el propio mundo material:

«Muchas veces la impresión que la vista de la naturaleza produce en nosotros se debe menos al propio carácter de la comarca que al día en que nos aparecen las montañas y llanuras alumbradas por el transparente azul de los cielos, o veladas por las nubes que cerca de la superficie de la tierra flotan. Del mismo modo, las descripciones de la naturaleza nos impresionan tanto más vivamente cuanto más en armonía se hallan con las necesidades de nuestra sensibilidad porque el mundo físico se refleja en lo más íntimo de nuestro ser con toda su verdad viviente. Cuánto da carácter individual a un paisaje el contorno de las montañas que limitan el horizonte en un lejano indeciso, la oscuridad de los bosques o de los pinos, el torrente que se escapa del centro de las selvas y se estrella con estrépito entre rocas suspendidas; cada una de estas cosas ha existido, en todo tiempo, en misteriosa relación con la vida interior del hombre» (Humboldt, 2003, 179). 
Afirmaciones como las precedente parecen poner en cuestión su carácter científico y materialista. Nos revelan a un Humboldt idealista, que sin embargo parece moverse cómodamente en su contradicción. La ciencia, con su método empírico, se ocupa de los elementos materiales de la naturaleza, estudia los fenómenos, las interrelaciones entre las partes, el encadenamiento de las causas y efectos. Camina con paso firme, aumentando día a día su conocimiento, avanzando en la reconstrucción de la unidad de la naturaleza. Pero por mucho que avance considera -al igual que Schelling y que Goethe- que su alcance siempre será limitado:

«Las ciencias experimentales, fundadas sobre la observación del mundo exterior, no pueden aspirar á una perfeccion completa, porque a ello se opone la naturaleza de las cosas igualmente que la imperfección de nuestros órganos. Jamás conseguiremos apurar la inagotable mina de la Naturaleza, ni generación ninguna podrá vanagloriarse nunca de haber abarcado la totalidad de los fenómenos» (Humboldt, 2005 a, t. I, 72-73)

Sin embargo, a través de la percepción sensible del paisaje y de las representaciones artísticas del mismo, se puede aprehender de manera intuitiva la «totalidad», la «unidad»y la «armonía» de la naturaleza, que se nos presenta entonces como indisoluble. Un camino de conocimiento que han explorado los filósofos de la naturaleza a través del entendimiento especulativo, y en cuyas puertas él se ha detenido, aunque reconociendo sus logros y -como ya se vio- sin considerarlo contradictorio.

«Un cuadro físico de la Naturaleza no debe pasar del límite en que comienza la esfera de la inteligencia, y donde la mirada se pierde ya en otro mundo diferente: marca ese límite, le señala, pero no le traspasa» (Humboldt, 2005 a, t. I, 384).

\section{3. ¿Paisaje geográfico en Humboldt?}

Ahora bien, ¿juega el paisaje geográfico en sí, tal y como se entendió en la primera mitad del siglo XX, como fisonomía objetiva de la naturaleza, algún papel en la órbita científica del conocimiento? Realmente, su papel en este terreno parece claramente secundario en su obra. En primer lugar, utiliza un concepto de paisaje reduccionista (incluso dentro del medio físico al que se refiere), en el que la vegetación no es sólo el elemento dominante de la fisonomía, sino prácticamente el único. No se trata de una opción inconsciente, sino explícita y argumentada:

«Este modo especial de distribucion geográfica, unido al aspecto de los vegetales, á su magnitud, á la forma de las hojas y de las flores, constituye el principal rasgo del carácter de cualquiera region; porque, lo repetimos, la vida animal, no obstante su variedad y su aptitud para despertar en nosotros sentimientos de simpatía ó de repulsion, presenta un aspecto sobrado móvil y fugaz para influir de una manera algun tanto eficaz sobre la fisonomía de un pais, siéndole por lo tanto casi extraño» (Humboldt, 2005 a, t. I, 372). 
Ello no le impide utilizar el paisaje geográfico para diferenciar y singularizar espacios. Así, por ejemplo, el carácter general de las estepas aparece bajo distintos aspectos o fisonomías:

«En todas las zonas presenta la Naturaleza el fenómeno de estas llanuras sin fin, pero en cada región ofrecen un carácter peculiar, una fisonomía propia determinada por la constitución del suelo, las diferencias del clima y la elevación sobre el nivel del mar» (Humboldt, 2003, 44).

Es, por tanto, un elemento de comparación y permite, a su vez, determinar las causas y los efectos de dichas fisonomías vegetales.

«Las miras del espíritu que compara y combina, es lo que nos lleva á descubrir en la individualidad de las formas orgánicas (en la Morfologia ó historia natural descriptiva de las plantas y de los animales), lo que tienen de comun con relacion á la distribucion climatérica de los séres; así como la inducion es la que nos revela las leyes numéricas en la proporcion de las familias naturales á la suma total de las especies, y á la latitud ó situacion geográfica de las zonas en que cada forma orgánica alcanza en las llanuras el máximum de su desarrollo. Estas consideraciones asignan un carácter elevado a la descripcion física del globo, por la generalizacion de sus miras, y nos hace concebir cómo el aspecto físico del paisaje, ó sea la impresion que nos causa la fisonomía de la vegetacion, depende de aquella reparticion local de las formas, del numero y del mas vigoroso crecimiento de las que predominan en la masa total» (Humboldt, 2005 a, t. I, 60)

Humboldt, por lo tanto, descubre la importancia de la fisonomía de la naturaleza para la singularización de los espacios geográficos, para su clasificación y comparación. Y ello, a mi modo de ver, constituye el elemento más novedoso y su aportación más destacada a la geografía del paisaje. Pero la explotación científica de tal recurso es aún en él realmente pobre. Las descripciones de sus elementos son poco precisas y con frecuencia se pierden en el ruido estético; pocas veces se hace referencia a la densidad de la vegetación, al porte y altura, a las características particulares de su entorno (más allá de la altitud y latitud). Utiliza el sistema fisiognómico o de «especies base» (Grunformen) (Verdú Schumann, 2008, 186) y no de formaciones vegetales. Y ello se debe a que lo que más le interesa es «la impresión» que dicha vegetación, como fisonomía, causa en el observador, «la impresión», por supuesto, subjetiva. Por otra parte, tampoco mantiene una sistemática en la descripción de los paisajes vegetales que identifica. En la Geografía de las plantas -que presenta quizás descripciones fisionómicas más próximas a lo que podríamos considerar paisajes biogeográficos- la descripción de la cliserie del Chimborazo define las regiones por una o dos especies, las que visualmente resultan más destacables: región de las plantas subterráneas (criptógamas), región de las palmas y plátanos (hasta más o menos los 1.000 metros), región de los helechos arbóreos (hasta más o menos los 1.700 metros)... En la descripción de esta última, por ejemplo, se dedica fundamentalmente a informar sobre la presencia simultánea del árbol de la quina, la Cinchona, y de la distribución de éste (y sus distintas variantes) en otros escenarios de distin- 
tas altitudes. En general, se preocupa mucho más de referir las especies correspondientes a cada piso y confirmar la ley general de distribución de las plantas, que a describir y explicar propiamente el estado de ese paisaje (Humboldt, 1985, Cuadro, partes 3 y 4).

En absoluto significa esto que las descripciones paisajísticas humboldtianas carezcan de interés geográfico. No sólo lo tienen en la misma medida que las de otros grandes viajeros (Forster, Bougainville...), como magníficas guías que permiten aproximaciones particulares al conocimiento de los países descritos, sino que además en su caso dichas descripciones parecen guiadas por una mayor intencionalidad geográfica, como definidoras de espacios singulares susceptibles de comparación. Carecen, sin embargo, de sistemática, de organización de los elementos que lo componen en orden a descubrir sus relaciones; carecen, en definitiva, de su elaboración como objeto de análisis geográfico.

\section{CONCLUSIÓN}

En los Museos Vaticanos, en las estancias de Raphael, un mural conocido como «La Escuela de Atenas» representa al grupo de los más conocidos filósofos griegos. El centro lo ocupan Platón señalando con el dedo hacia arriba, al mundo de las ideas, y Aristóteles con la palma de la mano hacia abajo, indicando que nada existe fuera de la materia. Y ocupan el centro no sólo por ser considerados en el Renacimiento como los más grandes filósofos de la Antigüedad, sino también por representar los dos principales paradigmas del pensamiento, dos formas de ver el mundo consideradas opuestas. Desde entonces, el debate entre materialistas e idealistas ha recorrido toda la historia de la filosofía, alcanzando momentos de gran especulación idealista, como el que dominó la filosofía alemana de finales del siglos XVIII y primera mitad del XIX, en el que destacaron figuras como Fichte, Novalis, Shelling, los hermanos Schegel, Hölderlin, Hegel, Herder, Goethe o Shiller. Una situación bien excepcional, ya que en otros lugares de Europa, como Francia o Inglaterra, predominaban concepciones materialistas y empiristas en aquellos tiempos. Unido al hechizo de la naturaleza, que por entonces cautivó a filósofos, artistas y científicos en todo Occidente, el idealismo romántico alemán desarrolló una filosofía de la naturaleza que, en determinados pensadores, adquirió una gran relevancia. Humboldt parece hallarse, como hemos visto, mucho más influenciado por ella de lo que podría pensarse en función de su trayectoria científica empirista y racional, incluso de la concepción materialista que hace explícita en ocasiones. Probablemente ningún científico ni intelectual alemán podía escapar en aquellos tiempos al influjo de esta filosofía, que parece reaccionar frente al positivismo materialista que suponía la separación de la ciencia y el arte, pero también de la naturaleza y el hombre. Una escisión que implicaba el alejamiento del hombre del conocimiento racional de la naturaleza, reservado a una ciencia cada vez más compleja y basada en modelos abstractos. Una división que -como ha señalado Manuel Sacristán- se corresponde con la propia diferenciación técnica del trabajo en un determinado régimen de producción y otro de apropiación, es decir, una diferenciación característica del sistema capitalista. Bajo esas condiciones de separación, la ciencia se abría camino hacia un desarrollo tecnológico considerado uno de los grandes motores del progreso de la sociedad burguesa (Sacristán, 1967, 27), subordinando plenamente a la naturaleza, sin considerar su posible deterioro ni el agotamiento de los recursos no renovables. 
Humboldt participó, sin duda, en esa trayectoria científica, pero manteniendo, al tiempo, un discurso holista de la naturaleza, una perspectiva integradora, armoniosa y panteísta que recuerda demasiado a la sostenida por Goethe y por los filósofos idealistas románticos alemanes. A pesar de la evidente contradicción, su discurso no se encuentra excesivamente tensionado; parece moverse en dos ámbitos independientes: el analíticomaterialista, por el que avanza en el conocimiento de las leyes de la naturaleza y en la concatenación de los fenómenos, y el intuitivo-idealista, que le permite aproximarse a la idea de naturaleza como totalidad. Una vía especulativa que en realidad no recorre gnoseológicamente. Parece como si en su caso fuese una cuestión de fe; creía irreflexivamente en esa naturaleza total y armónica como se cree en una deidad. Nunca especuló sobre tal idea ni estableció un método intuitivo de aproximación al estilo de Goethe o de Schelling; creyó reconocer esa vía en las impresiones sensibles percibidas ante la belleza de los paisajes. Pero en todo caso y finalmente, esa idea idealista de naturaleza se impone y condiciona todo su discurso. En el momento en que se deshace del andamiaje (los datos de sus elaboraciones empíricas) y aborda la síntesis (como hace en Cosmos), el holismo idealista lo tiñe todo y con mucha frecuencia -como ha puesto de manifiesto Ortega Valcárcel- reconocemos una idea de globalidad y unidad que recuerda más las representaciones clásicas del cosmos, de raigambre medieval, que las de una ciencia empírica moderna (Ortega Valcárcel, 2000, 129).

Totalidad integradora, convivencia armónica del hombre con la naturaleza, influencia de ésta sobre la moralidad, ideas antiguas que tomaron un gran auge en la Ilustración y primer romanticismo y que hoy algunos quieren ver como antecedentes de la conciencia ecológica. Por cierto que también Schelling (Arturo Leyte, Introducción a Shelling, 1996, 50) y Goethe (Sánchez Meca, Estudio preliminar a Goethe, 2007, XVIII) han sido considerados como precursores del ecologismo con argumentos similares. Lo cierto es que en su tiempo aquellas ideas eran más fáciles de mantener, en la medida en que, por una parte, desconocían por ejemplo las recientes teorías del caos del Universo, y por otra, porque en esa época y en los escenarios estudiados el impacto y fuertes alteraciones que esta sociedad provocaría en la naturaleza, aún no eran lo suficientemente apreciables (Herrera Piqué, 2010, 178-179). Pero estas ideas se desvanecieron con el propio Humboldt. El mismo año de su muerte, 1859, se publicaba El origen de las especies de Charles Darwing, obra con la que se imponía una nueva concepción dominada por la hostilidad de la naturaleza, la adaptación de los más fuertes y la desaparición de los más débiles: «la guerra de la naturaleza, del hombre y de la muerte» (Álvarez López, 1959, 370). Hoy el discurso de la integración armónica del hombre y la naturaleza parece sencillamente incompatible con el sistema capitalista actual (Tanuro, 2011). La alternativa de desarrollo sostenible no parece estar llevándonos demasiado lejos en la búsqueda de una nueva senda de equilibrio con la naturaleza. A nivel global, nadie duda ya de que las alteraciones que está provocando o acelerando el cambio climático -cuyos efectos se están dejando notar y pueden tener consecuencias cada vez más catastróficas en algunas partes del mundo- son el resultado de determinados sistemas energéticos (combustión de carbono) que los grandes productores se niegan a sustituir. A nivel local o regional, el fracaso de las políticas medioambientales y paisajísticas en cuanto existen intereses económicos resulta también absolutamente evidente. 
En lo que hace al paisaje, hemos visto como en el idealismo alemán éste pocas veces abandona el cuadro. Después de emanciparse como tema autónomo en la pintura del siglo XVII, alcanzará especial relevancia durante el romanticismo, momento en el que también parece desvincularse del mimetismo y se espiritualiza. Pero sigue sin salir del cuadro o de la descripción poética. Sólo en Goethe detectamos una tímida consideración al paisaje independiente de la representación artística, de la obra de arte; aunque no de la representación estética formada a través de la contemplación sensible de la naturaleza. En todo caso, tanto en Schelling como en Goethe el paisaje, como obra de arte o como contemplación estética y sensible, juega un papel fundamental en su aproximación a la naturaleza como totalidad. Por su parte, en la concepción humboldtiana podemos detectar una doble dimensión del paisaje no explícita ni consciente en él: la de representación estética de la naturaleza procedente de la contemplación individual o plasmada en imágenes pictóricas o poéticas, y la de fisonomía en sí de la naturaleza, útil en el terreno geográfico para identificar y comparar espacios o para determinar causalmente las combinaciones de sus elementos. De ambas dimensiones, en mi opinión, la modernidad y, sobre todo, originalidad está en la segunda, ya que la vertiente estética procede más bien de la filosofía idealista romántica alemana. Pero esta segunda dimensión del paisaje, la propiamente geográfica, aparece desdibujada y mal aprovechada. El análisis del paisaje como tal no se encuentra desarrollado porque dicho objeto aparece aún excesivamente indefinido. Si bien quizás puedan resultar exageradas opiniones como la de Hard (1969, 153, citado por Kohlhepp, 2003-204, 51) que considera que el paisaje nunca fue un objeto de investigación para Humboldt, sino únicamente un estímulo estético y un tema de descripción literaria, lo cierto es que éste tenía aún muy poco de paisaje geográfico (entendido aquí como fisonomía objetiva del espacio) y mucho de representación estética. Eso explica en parte que hubiera que esperar aún más de medio siglo para que el paisaje propiamente geográfico, emancipado de sus connotaciones estéticas, fuese formulado como objeto independiente por los geógrafos alemanes de la Landchaftsgeographie. ¿Se le puede considerarse precursor de la concepción fenomenológica de paisaje geográfico (objetivo y subjetivo a la vez)? Quizás, pero no olvidemos que para Humboldt la vertiente subjetiva es mística, panteista, permite contemplar la totalidad y la armonía de la naturaleza, e incluso la vertiente objetiva, la descripción fisionómica, apenas se despega de las impresiones, de la mirada. Ciertamente algunos geógrafos actuales parecen sentirse próximos a esa idea, pero desde luego tiene poco que ver con la definición que se ha impuesto en la Convención europea, que aunque parece responder a esa misma concepción porque explicita la doble vertiente de lo objetivo y lo subjetivo del paisaje, es en realidad fundamentalmente instrumental, orientada a la ordenación, valoración y mercantilización del espacio. Pero entrar en esta diferenciación es ya otro tema para el que se carece de espacio en este artículo.

\section{BIBLIOGRAFÍA}

ÁLVAREZ LÓPEZ, E. (1959): «Para un ensayo sobre la trayectoria científica de Alejandro de Humboldt». Estudios Geográficos, n 76.

ARNALDO, J. (2008): «Goethe: El paisaje como imagen», en Johann Wolfgang von Goethe. Paisajes. Catálogo de la Exposición celebrada en el Círculo de Bellas Artes 
de Madrid entre el 31 de enero y el 6 de abril de 2008 (comisarios: J. Arnaldo y H. Mildenberger).

BESSE, J-M. (2010): La sombra de las cosas. Sobre paisaje y geografía. Madrid: Biblioteca Nueva. Paisaje y Teoría.

BOTTING, D. (1995): Humboldt y el Cosmos. Barcelona: Ediciones Serbal.

BOUGAINVILLE, L. A. de (1966): Viaje alrededor del mundo. Madrid: Espasa Calpe.

CARUS, C. G. (1992): Cartas y anotaciones sobre la pintura de paisaje. Madrid: Visor.

D’ANGELO, P. (1999): La estética del romanticismo. Madrid: Visor.

DIDEROT, D. (1992): Sobre la interpretación de la naturaleza. Barcelona: Anthropos.

FARINELLI, F. (2009): «El don de Humboldt: el concepto de paisaje», en Clara Copeta y Rubén Lois [Eds.]: Geografía, paisaje e identidad. Madrid: Biblioteca Nueva.

FERNÁNDEZ LORENZO, M. (2001): «Schelling y el empirismo». Teorema, vol. XX/1.

FLÓREZ MIGUEL, C. (2010): La filosofía en la Europa de la Ilustración. Madrid: Síntesis.

GOETHE, J. W. von (2002): Goethe y la Ciencia, selección de textos e introducción de Jeremy Naydler. Madrid: Ediciones Siruela.

GOETHE, J. W. von (2007): Teoría de la Naturaleza, estudio preliminar, traducción y notas Diego Sánchez Meca. Madrid: Técnos.

GOETHE, J. W. von (2009): Viaje a Italia. Barcelona: ZETA.

GÓMEZ ACOSTA, E. (2010): «Humboldt y el exotismo», Revista Geográfica Venezolana, vol. 51 (2).

GÓMEZ MENDOZA, J. (2008): «La mirada del geógrafo sobre el paisaje: Del conocimiento a la gestión», en Javier Maderuelo [dir.]: Paisaje y territorio. Madrid: Abada Editores.

GÓMEZ MENDOZA, J, J. MUÑOZ JIMÉNEZ y N. ORTEGA CANTERO (1994): El pensamiento geográfico. Madrid: Alianza Editorial Textos ( $1^{\text {a }}$ edición 1982).

GÓMEZ MENDOZA, J. y SANZ HERRÁIZ, C. (2010): «De la biogeografía al paisaje en Humboldt: pisos de vegetación y paisajes andinos equinocciales». Población \& Sociedad, $\mathrm{n}^{\circ} 17$.

HARD, G. (1969): «Kosmos» und «Landschaft». Kosmologische und landschaftphysiognmische Denkmotive bei Alexander von Humboldt und in der geographischen HumboldtAuslegung des 20. Jahrhunderts», en Pfeiffer, H (ed.): Alexander von Humboldt. Werk und Weltgeltung. Múnich.

HERRERA PIQUÉ, A. (2010): Humboldt, América y Las Afortunadas. Madrid: Editorial Rueda.

HOFMANN, W. (2008): «Ve en lo finito hacia todas partes», en Johann Wolfgang von Goethe. Paisajes. Catálogo de la Exposición celebrada en el Círculo de Bellas Artes de Madrid entre el 31 de enero y el 6 de abril de 2008 (comisarios: J. Arnaldo y H. Mildenberger).

HUMBOLDT, A. von y BONPLAND, A. (1985): Ideas para una geografía de las plantas. Más un cuadro de los países tropicales. Bogotá: Jardín Botánico José Celestino Mutis. Biblioteca Virtual Luís Ángel Arango.

http://www.banrepcultural.org/blaavirtual/geografia/geoplan/indice.htm

HUMBOLDT, A. von (2003): Cuadros de la Naturaleza. Traducción de Bernardo Giner de los Ríos. Madrid: Catarata. 
HUMBOLDT, A. von (2005a): Cosmos ó Ensayo de una descripción física del mundo, vertida al castellano por Francisco Díaz Quintero. Madrid, 1851-1852. Edición facsímil publicada por la Universidad de Córdoba. Tomos I y II.

HUMBOLDT, A. von (2005b): Del Orinoco al Amazonas. Viaje a las regiones equinocciales del Nuevo Continente. Madrid: Planeta.

HUMBOLDT, A. von (2010): Vistas de las Cordilleras y monumentos de los pueblos indígenas de América. Madrid: CSIC.

KOHLHEPP, A. von (2003-2004): «Reconocimiento científico del viaje de Alexander von Humboldt por los trópicos latinoamericanos (1799-1804) desde una perspectiva geográfica. Población \& Sociedad, $\mathrm{n}^{\circ}$ 10-11.

MARTÍNEZ DE PISÓN, E. (2008): «La recuperación del paisaje. Una mirada del proceso de retorno desde la geografía española», en MARTÍNEZ DE PISÓN, E. y N. ORTEGA CANTERO [ed.]: La recuperación del paisaje. Madrid: Universidad Autónoma de Madrid/Fundación Duques de Soria.

MAS, S. (2004): «Goethe y Kant: Arte, naturaleza, ciencia», Éndoxa: Series Filosóficas, nº 18.

MELÓN, A. (1960): Alejandro de Humboldt. Vida y obra. Madrid: Ediciones de Historia, Geografía y Arte.

MEYER-ABICH, A. (1985): La filosofía de Alejandro de Humboldt. Biblioteca Virtual Luís Ángel Arango.

http://www.banrepcultural.org/blaavirtual/geografia/geoplan/anexfilo.htm

MINGUET, Ch. (2003): Alejandro de Humboldt historiador y geógrafo de la América Española (1799-1804). Traducido por Jorge Padín Videla. México: Centro Coordinador y Difusor de Estudios Latinoamericanos de la Universidad Autónoma de México.

MÖRNER, M. (1999): «Alejandro de Humboldt. La parte venezolana de su «Viaje» y otros relatos de viajeros a comienzos del siglo XIX». Conferencia en la Biblioteca nacional de Estonia, 30 de junio de 1999.

ORTEGA CANTERO, N. (2006): «Entre la explicación y la comprensión: El concepto de paisaje en la geografía moderna», en J. Maderuelo [Dir.]: Paisaje y pensamiento. Madrid: Abada Editore.

ORTEGA VALCÁRCEL, J. (2000): Los horizontes de la Geografía. Barcelona Ariel.

POVEDANO MARRUGAT, E. (2008): «Las enseñanzas artísticas y Humboldt», en Actas del simposio Alexander von Humboldt entre volcanes. La Laguna: Universidad de La Laguna.

RAMÍREZ, M. T. (2007): «Ilustración y cultura. Kant y Hegel: dos modelos de concepto de cultura en la filosofía moderna». La lámpara de Diógenes, $\mathrm{n}^{\circ}$ 14-15.

SACRISTÁN, M. (1967): «La veracidad de Goethe», en M. Sacristán: Lecturas: 1 Goethe, Heine. Madrid: Editorial Ciencia Nueva, colección «Los Complementarios»

SCHELLING, F. W. J. (1996): Escritos sobre filosofía de la naturaleza. Madrid: Alianza editorial.

SCHELLING, F. W. J. (2004): El «Discurso de la Academia». Sobre la relación de las Artes Plásticas con la Naturaleza (1807). Madrid: Biblioteca Nueva.

SOSA HENRÍQUEZ, J. y CASTRO MORALES, F. (2008): «Preparativos científicos y estéticos para el viaje canario-americano», en Actas del simposio Alexander von Humboldt entre volcanes. La Laguna: Universidad de La Laguna. 
TANURO, D. (2011): El imposible capitalismo verde. Madrid: Viento Sur.

VERDÚ SCHUMANN, D. A. (2008): «De Post y Eckhout a la escuela del río Hudson: Modelos y fortuna del paisaje humboldtiano», en Actas del simposio Alexander von Humboldt entre volcanes. La Laguna: Universidad de La Laguna.

VV.AA. (1994): Fragmentos para una teoría romántica del arte (antología y edición Javier Arnaldo). Madrid: Tecnos. 